\section{THE CAVENDISH LECTURE} ON

\section{ELININATION \& ITS USES IN PREVENTING IND CURING DISEASE.}

Delivered before the West London Medico-Chirurgical Society.

By T. TAUDER BRUNTON, M.D., D.Sc.EdrN., LL.D. (HoN.) Aberd., F.R.C.P., F.R.S.,

$\Lambda$ ssistant Physician, and Iecturer on Materia Medica and Therapeutics at t. Bartholomew's Hospital.

IT seems to me that one of the most marvellous definitions ever given is that of dirt as "matter in the wrong place." The matter need not be in itself objectionable. It may be, on the contrary, exceedingly valuable and useful, provided it be in its proper place and fulfilling its proper function, and yet it becomes dirt at once when put in the wrong place. The pipeclay which is used to keep the soldier's belt clean becomes dirt when it gets upon his uniform, and the blacking which lends lustre to our boots and is used to keep them clean, as it is termed, at once assumes the character of dirt, and exceedingly objectionable dirt, if we put up those boots on a chintz-covered sofa, leaving a black smudge on the fair surface of the fabric.

The utility of things which most people would agree to call dirt is shown by the care employed in sifting cinders, and in separating rags and bones from the contents of our dustbins. But the dust contained in these bins is a most unmitigated nuisance to the unfortunate householder who cannot get it removed. I do not know any topic more calculated to excite a lively conversation amongst householders in London, at any rate, than that of dustbins and drains. The mere mention of either of these words has an effect quite different from that of the "apple of discord," for its effect is a most wondrous concord, everyone having the same tale to tell of the neglect of the dustmen and the iniquities of plumbers.

The dustbins are the receptacles for the solid refuse of our houses-the dust, the ashes, the cinders, the odds and ends of dry material-which accumulating in our rooms would render them dirty and disagreeable; but the drain pipes are the channel by which the soluble and liquid refuse of our houses is carried away, and any interference with them is still more serious than the non-removal of our dust.

It is only in highly complex communities that the difficulty of removing refuse, either solid or liquid, is felt to an extreme degree. A single individual travelling all by himself in the country has no difficulty whatever. In villages the difficulties are but slight, and even in large camps they may be overcome in a very simple manner, as is shown by that hygienic law of Moses: "Thou shalt have a paddle upon thy weapon; and it shall be when thou wilt ease thyself abroad thou shalt dig therewith and shalt turn back and cover that which cometh from thee.": But in cities like London, Paris, Berlin, or Vienna, the difficulty of eliminating the refuse is very great, and enormous expenditure is required to effect it. Each unit in the population contributes to the total amount, and as the population grows, the difficulty increases.

But in large towns the whole refuse of a house does not at once find its way into the dust-bin or the sink. The worn-out furniture, the cast-off clothes and disused utensils which are lumber and rubbish in the houses of the rich, find their way as useful articles into those of the poor, and after a further period of service, descend still lower in the scale of society, passing perhaps through many grades before they are thrown away as absolutely worthless. Even after their fragments have found their way into the dust heap they are again picked up by scavengers, conveyed to mills or factories and, after being there transformed into a different shape, are again employed for other purposes.

Now there is a wondrous unity in life and living beings, and the same process which we find going on in towns and villages occurs also in the living beings which compose their population. Nay more, it exists in the tissues and cells of which these living hodies are composed, and even in the uni- cellular organisms which constitute the simplest forms of life on the surface of this globe. These unicellular organisms are now attracting much attention, for they are the earth's scavengers who tear up the old clothes, crush up the old bones and burn off the ashes of the world which would otherwise accumulate and render life impossible. But these lowly organisms are not content with breaking up dead matter; they magnify their office and, by attacking living beings, they produce diseases which may lead to the death, dissolution, and ultimately to the complete disappearance of the man or beast they attack. Such unicellular organisms, as a rule, have no difficulty in getting rid of the products of waste which are formed by them as well as by the higher animals. As a rule they live and grow in some fluid, and their own movement through the fluid brings them into contact with fresh layers of it from which they obtain new nutriment and which also washes away their refuse. Should this refuse accumulate to too great an extent, as it does when the fluid is too crowded by the presence of an enormous number of microbes, the refuse products will kill these microbes, just as the unfortunate persons confined in the Black Hole of Calcutta were suffocated by the products of their own respiration.

But just as the broken victuals and old clothes of the rich, regarded by them as simple rubbish, can be utilised by their poorer neighbours, so the fluid in which one class of microbes can no longer grow forms a most suitable soil for others. Thus the liquid in which yeast can no longer grow forms a most suitable soil for the acetic bacillus, and when this in turn has ceased to grow, its place is taken by putrefactive bacilli, and these in their turn are succeeded by moulds.

When unicellular organisms become agglomerated together as in sponges, the difficulty which each organism has in getting rid of its waste material and in obtaining new nutriment is increased, and those cells which are unfavourably placed would probably die very quickly, either from lack of nutriment or from suffocation by their own waste, were it not that this untoward issue is provided against by a peculiar arrangement. Some of the cells become furnished with cilia, which keep up a constant current of water through the interstices of the sponge, and thus bring the fixed cells into a similarly favourable condition as their free swimming congeners, with this difference: that, in the case of the free swimming cell, it moves through the fluid in which it lives, while in the case of the fixed cell the fluid flows over it.

This latter arrangement is the one which exists in most of the cells of the higher organisms such as man. Although some cells, like the leucocytes of the blood, swim freely through the fluid which nourishes them, all the fixed cells of which the tissues are formed are nourished by the lymph which flows around them or between them. A constant current is kept up in this lymph by the mere pressure due to exudation from the capillaries on the one hand, and to absorption by the veins and lymphatics on the other, aided by pressure on the tissues caused by movements. Only in one place, the central canal of the spinal cord, where the delicacy of the tissues requires a constant flow of nutrient fluid, and yet demands an absence of pressure which might injure the nervous structures, is the current of lymph kept up by ciliary motion, as it is in sponges.

As Claude Bernard well puts it, the cells of which our bodies are composed do not live in air. They live in a liquid internal medium, which at the same time supplies nutriment and oxygen and removes waste products. So long as this nutritive medium continues to fulfil its functions, the cells of which our bodies are composed live and grow with perfect indifference to our external surroundings; and so long as a man holds his breath, so that the fluid medium is unaltered, it is a matter of indifference whether he has his head in a bag of oxygen or in a brewer's vat filled with carbonic acid.

But the fluid medium or lymph very quickly becomes altered by the living cells, which drain it of its oxygen and pour into it their waste products, and in the course of a few minutes it would become quite unable to support their life, were it not gaining supplies from without of oxygen and nutriment, and eliminating or destroying the waste product poured into it. I say destroying, because when the lymph passes into the blood the waste products appear, to a certain extent at least, to undergo oxidation, just as the sewage of villages high up the Thames becomes oxidised or destroyed [1590] 
before it reaches the mouth of the river or the open sea. But various conditions may tend to interfere more or less with the discharge of the sewage from the cells, as well as with their supply of nutriment and oxygen, and it is with this discharge of sewage or elimination of waste products from the cells which compose our tissues into the blood and its excretion from the body as a whole that we have particularly to do to-day.

It is not merely the elimination of the natural waste products of our tissues that we have to consider, but the elimination of waste products formed within our bodies by disease germs which have entered them. These disease germs, consisting as they do chiefly of bacilli or micrococci, resemble the cells of our bodies in the fact that they also may be destroyed by their own waste products, but when they enter our bodies the substances they produce-harmful though they might be, if in excess, to the bacilli themselves-are usually still more harmful to the cells of the tissues, and so weaken them as to give the microbes a better chance of success in the struggle between them and the organism into which they have entered. Though opinions may differ as to the exact mode in which the organism destroys intruding microbes, or intruding microbes destroy the organism, there is no doubt about the fact that a struggle does exist between them, and the recent experiments which have been made on such a large scale with Koch's tuberculin have shown that this fluid, although sometimes useful and productive of benefit to patients, not infrequently has an opposite action, and appears to assist the development and growth of the tubercle bacilli already present in the lungs or elsewhere. The apparently contradictory results obtained by the use of tuberculin seem to be explained by the observations of Brieger and Fraenkel in regard to diphtheria. These observers have discovered that the diphtheritic bacilli produce two substances, one of which is toxic to an animal, and the other of which is protective. These substances differ in their power of resisting heat, the toxic substance being destroyed at a temperature of $55^{\circ} \mathrm{C}$. to $60^{\circ} \mathrm{C}$., while the protective resists a temperature not much below the boiling point. These substances appear closely allied, and it is just possible that one may be transformable into the other. What their relationship to one another is we do not at present know, but if we look at the vegetable kingdom we find that in numerous instances poisons closely allied chemically to one another are present in the same plant, but have an antagonistic action to one another. Thus in calabar bean we have physostigmine and calabarin, of which the latter stimulates and the former depresses the spinal cord ; and jaborandi contains two alkaloids, pilocarpine and jaborine, having entirely different actions, and, indeed, jaborine antagonises the action of pilocarpine. Many alkaloids contained in the same plant seem to have a simple relation to one another; either the one contains the elements of water more or less than the other, or an atom of hydrogen in the one is replaced by a molecule of methyl in the other. Whether some such simple relationship as this exists also in the products of hacteria we do not yet know, but there is little doubt that further researches will soon throw much light on the chemical nature of bacterial poisons. One noticeable point in regard to the resistance of animals to such poisons is that an abundance of glycogen in the liver increases its power to destroy the action of such poisons as pass through it. This power diminishes as the glycogen disappears, and what is true for the liver is probably true for other parts of the body. At any rate, we know that when animals are starved the glycogen disappears both from the liver and the tissues, and starvation greatly increases the liability of an animal to succumb to infection. But, putting aside the question of neutralisation of bacterial poisons by the lymph or tissues, it is evident that if the toxic products of any bacillus can be washed out of the organism, that organism will have a better chance, and experience confirms the theoretical view that free elimination, both by the kidneys and the bowels, is useful treatment in infective diseases.

Turning again to the normal products of tissue change, we note that probably the most important parts of a cell are its nitrogenous components or proteids. The chief products of nitrogenous waste are urea and uric acid, and the relative quantity of each varies in different classes of animals. The urea forms the chief product of waste in the amphibia, but in the reptilia and in birds the waste appears almost entirely in the form of uric acid combined with bases. In man we have a mixed condition, as the waste occurs partly in the form of urea and partly in the form of uric acid, the proportion of acid to that of urea being about 1 to 33 . It is usually supposed that there is a greater tendency in some persons to the formation of uric acid than in others, and that this tendency is associated with a gouty or rheumatic diathesis. In a number of exceedingly interesting and valuable papers Dr. Haig has shown that the excretion of uric acid is greatly influenced by the comparative alkalinity or acidity of the blood, and that the amount of acidity ${ }^{2}$ may be made to vary within very considerable limits by the kind of food, by the process of digestion, and by the use of various drugs.

There are certain parts of the body more especially in which the uric acid, wherever it may be generated, has a tendency to get stored up, and this is especially the case in the spleen and the joints, which may be compared to dustbins. Whenever the blood becomes more strongly alkaline than usual it tends, like an active housemaid, to sweep up the uric acid dust out of these bins, with the result of causing great discomfort to the organism generally, for the uric acid, thus sent on its travels, attacks the nerve centres and the vessels, producing headache and depression of spirits, so that gouty people will frequently object to the use of alkalies because, as they say, they are very lowering. Acids, on the contrary, prevent the blood from taking up the uric acid, and lead to its being concentrated in the dustbins already referred to, so that acids relieve the depression, remove the headache, but, at the same time, tend to cause pain in the joints and accumulation of uric acid in the spleen. Here it lies without producing any inconvenience for the time, but it may possibly be stored up to such an extent as to cause great discomfort or even danger when this large dustbin comes to be cleared out.

A year or two ago I had a very striking case illustrative of Dr. Haig's views. A gentleman, who had suffered from chronic malaria, had an enormously enlarged spleen. That organ began to contract, and simultaneously the patient began to suffer from repeated attacks of renal colic, due to small uric acid calculi, at intervals of two or three weeks. So frequent were these attacks that I thought he must have had an accumulation of small stones in his kidney, for I did not fancy he could form the concretions sufficiently rapidly to cause such frequent recurrence of the renal colic. Postmortem examination, however, showed that I was mistaken, for there was no calculus whatever in either kidney.

Retention of uric acid in the spleen, according to Dr. Haig, is accompanied by its absence from the blood, and consequently by a feeling of well-being and jollity, which may, however, pass into an entirely opposite condition when the uric acid, which has been stored up during this period of retention, again finds its way into the circulation. Thus while a glass or two of champagne, by increasing acidity, drives the uric acid out of the blood, and consequently gives rise to hilarity and happiness in the person who has taken it, it will give a gouty man twinges in his joints, by causing the uric acid to lodge in them, and may cause much subsequent headache and depression when its first stimulant effect has passed off and the imprisoned uric acid again enters the circulation.

Even more serious consequences than depression and discomfort may, according to Dr. Haig, be produced by the rapid removal of uric acid from its chief dustbin or storage place-namely, the spleen-into the circulating blood; for, instead of only affecting the mental faculties, it may attack the heart with fatal results. As an instance, he gives the death of the late Canon Liddon, who had recovered from an attack of gout in the head, and was feeling fairly well even after the fatigue of a railway journey, but suddenly fainted shortly after breakfast, and died. Dr. Haig's explanation of this is that, during the period of comparative well-being, the uric acid had been stored up, and when the blood became more alkaline, as it does during digestion, and dissolved a part of it out, the liberated uric acid contracted the arterioles, thus raising the tension so that the heart was unable to overcome it, and causing fatal syncope.

The blood is never acid, but diminished alkalinity may, for the sake of convenience, be spoken of as comparative acidity. 
Haig's theory of the storage of uric acid is, I believe, very much the same as that of Sir A. Garrod, namely, that this substance is formed in the kidneys out of waste products derived from the nitrogenous tissues generally or from the liver. Part of it is at once excreted, but part of it may return from the kidneys, and either circulate in the blood or get stored up in the spleen. If we return to our analogy of the dust in the house, it is as if the ashes, crumbs, and waste vegetables were thrown together into an ash bucket to be emptied, but, if this emptying were imporfectly done, the remnants would be thrown into a dustbin within the house, and could not be cleared out directly to the outside, like the ash bucket, but would require to be emptied by bringing it through the passages of the house, which would lead to much discomfort.

The alkaline constituents in the blood are the natural solvents of uric acid, and anything that increases their proportion in the blood renders the uric acid more soluble, so that it is more readily removed from its place of storage and brought into the general circulation, where it produces manifold discomforts. Thus it is that alkaline remedies in gouty patients are so apt to give rise at once to the complaint of their being lowering, not because they have a depressant action of their own, but because they withdraw the uric acid from its lurking place, and allow it to act upon the nervous system, thus producing depression.

The alkalinity of the blood is increased when the materials of gastric juice are withdrawn from it during digestion, and at this time not only is the urine frequently neutral or alkaline, but the gouty man may suffer from the discomfort due to the circulating uric acid, and fall asleep over his paper after breakfast, or feel stupid and drowsy after lunch when he ought to be attending to his business.

On the other hand, anything that diminishes the alkalinity of the blood- such as acids or wines, and condiments containing acid, nux vomica, opium, and iron-tends to drive the uric acid out of the blood into its storehouses, and so produces a feeling of well-being which may, however, be only temporary and illusory, as the uric acid is not eliminated from the body but only stored away within it, and when the blood becomes alkaline after another meal or after a dose of soda, all the uncomfortable feelings produced by uric acid may again torment the patient.

Again returning to our illustration. If the contents of our dustbinwere carried through our passages, they would be flying about and great discomfort would ensue; but if we took care to wet each bucketful with a deodorising solution there would be neither flying dust nor disagreeable smell, and the clearing out would be done with a minimum of trouble. In the gouty man's body salicylic acid seems to have a similar effect to wetting the dust; it accelerates the elimination of uric acid while preventing its disagreeable action, and Dr. Haig advises a prolonged course of this drug as a means of permanent cure in gouty patients.

It is hard to say at present what the natural solvent of uric acid is in the body, for it is quite clear that people generally have not got salicylic acid regularly circulating in their blood. Sir William Roberts considers that the pigmentary substances which one finds in the urine probably have a solvent action, and it has occurred to me that possibly a pyrocatechin, which is almost constantly present in the urine, and is nearly related chemically to salicylic acid, may be one of the natural solvents, but I have not yet been able to test this idea experimentally.

I have entered thus fully into Dr. Haig's view of the pathology of gout and the elimination of uric acid because I regard his work as one of the most important contributions which have been made for many years to our knowledge of gout and rheumatism. I do not myself think we have yet got to the bottom of the question. In all probability we shall find that the proteid waste which yields the raw material for uric acid is quite as important, or more important, than the uric acid itself, but Dr. Haig has, at any rate, supplied us with a useful work ing hypothesis, which may enable us both to foretell the results of certain indiscretions in diet or regimen in gouty people, and to supply us with the means of alleviation $\mathrm{rr}$ cure. Besides the salicylate of soda, upon which he lays so much stress, we find that gouty people are accustomed to trust to baths and watering-places of all sorts for relief, and no doubt a visit to Homburg, Aix-les-Bains, Carlsbad,
Marienbad, Brides-les-Bains, Baden-Baden, Wiesbaden, Harrogate, Bath, or Strathpeffer will all greatly improve the health and often protect patients from gouty symptoms for many months, or even years, afterwards.

In visiting all these watering-places one is struck by the diversity of the constituents of all those world-famed springs and the constancy of one ingredient, namely, water. In watching the patients one sees that people who at home never touch a drop of water pure and simple from year's end to year's end, taking it only in the form of wine, beer, tea or coffee, will, at a spring, drink tumbler after tumbler of water containing common salt with minute traces of other thingsas at Wiesbaden or Baden-Baden-or the same constituent with rather more lime-salts at Homburg, sulphate of soda and carbonate of soda at Carlsbad or Marienbad, or sulphuretted hydrogen-as in Aix-les-Bains, Harrogate, or Strathpeffer. I do not mean to say that the saline or gaseous ingredients of these springs are without effect upon the organism - far from it-but at the same time I feel quite convinced that very many people would never require to go to wateringplaces if they would drink more water at home.

Water is the most universal solvent in the world. It is not only useful to wash out our closets and flush our drains, it has a similar effect in our bodies and tends to wash away the waste products from the cells of which our organs are composed, to clear out the uric acid, urea and phosphates through our kidneys and thus prevent renal or vesical calculi, and also to wash out our liver and prevent gall stones, while it helps to keep the bowels in action. The liver especially is an organ which suffers much from want of water, and I never see a gall stone without asking the patient " How much water do you drink?" Almost invariably the answer is "I hardly ever touch water. I am not a thirsty person," and on one occasion a lady called for a particular teacup, which held little more than a thimbleful, in order to show me how much she drank. On reckoning how much water she took in the st hours it came, as nearly as I could calculate, to 16 fluid ounces. What wonder then that she had a gall stone. The poor liver had not a chance to make decently fluid bile, and naturally there was a deposit. By making such people drink a big tumbler of water, and especially hot water every morning with or without some Carlsbad salts added to it, and, if necessary, repeating the hot water once or twice more in the day, the renewed formation of gall stones may frequently be averted, and symptoms of biliary colic, to say nothing of so-called biliousness, may be prevented for many years or perhaps entirely. But some patients will not do this at home, and if you were to tell a fashionable lady to get up at 6 oclock in the morning and walk round Grosvenor Square with a tumbler of hot water in her hand, taking a sip at it every three steps, to go on doing this for an hour together, then to buy at a confectioner's a penny roll and eat this without butter for her breakfast, with a small cup of coffee and nothing more, she would probably laugh in your face or apply to some one else for advice. But all this and more you secure by simply advising her to go to Carlsbad. There she finds everybody else doing the same thing, and instead of marching round and round all by herself or accompanied only by little boys who might point the finger of scorn at her, she finds herself in the company of all the fashionable visitors to the bath and marches to the music of a brass band. The company of others enables her to carry through the tiresome process and to comply with the troublesome restrictions, while the benefit she is sure to derive from it probably makes her feel so strong and happy that she swears by the place ever after, and returns to it again and again. For people who can afford it a visit to such places supplies the best means of cure, but for those who cannot an excellent substitute may be found in the daily consumption of hot water, if they will only have patience and perseverance in its use.

The process of washing out is not only useful in biliary calculus, it is of the utmost value in preventing renal gravel and calculi. The process may be carried on at home by means of hot water either alone or with the addition of a small quantity of some saline, such as bicarbonate or nitrate of potash. In cases where the patient dislikes hot water alone, a slice of lemon thrown on the top of it gives it a slightly agreeable taste, and may overcome the patient's repugnance.

The two watering places where patients with renal calculi 
chiefly go are Wildungen and Contrexéville, with its neighbours Vittel and Martigny-les-Bains. What strikes one in the waters of these places is that, in addition to other salts, they contain a very minute trace of iron, which appears certainly to be beneficial to the patients. It is supposed to act by astringing the mucous membrane of the pelvis of the kidney, and so allowing calculi to slip down more easily.

There are several other methods of cure which I believe owe their virtues to the fact that they produce pretty complete elimination of waste products by causing the patient unconsciously to imbibe a large quantity of water. These methods are the grape cure, the whey cure, and the milk cure. For the grape cure the patient resorts to some warm, sunny place, where the grapes grow well, and there eats many pounds in the course of the day, while other articles of diet are correspondingly diminished. The ripe grapes contain an enormous proportion of water and very little solid matter, so that the grape cure really comes to be a combination of water drinking and semi-starvation, greatly resembling the Carlsbad cure, to which an additional likeness is given by the laxative effects of the alkaline tartrates contained in the grape juice. The whey cure is very much the same, with the exception that, instead of eating grapes, people drink whey, and that the climate where the cure is carried out is usually a high and bracing sub-alpine one, instead of being soft and sunny. The milk cure is one frequently used in this country with great advantage, more especially in cases of typhoid fever, in chronic diarrhœa occurring in persons who have come from tropical climates, in glycosuria, albuminuria, and some cases of heart disease. Its advantage in typhoid fever is so universally acknowledged that one need hardly say anything about it, but I think it is possible that its efficacy may not be due merely, as is usually supposed, to the milk supplying a bland and non-irritating diet, but may possibly be due also to the waste products of the organism being washed out by the large amount of water which is either contained in the milk itself or added in the form of lime water or soda water to it. The results of an exclusively milk diet in chronic diarrhoea are sometimes quite astonishing, and a few months ago I had a letter from a patient who had been suffering from it for ten years, had tried all sorts of medicine in vain, had just come back from Carlsbad worse than he went, and had nearly given up hope of cure. I saw him only once, and told him that the medicine I gave him might do him good or might not, but that if he did not get well his only hope was to put himself on milk and milk only. This treatment, as he informed me by letter months afterwards, cured him as if by a charm.

In diabetes the milk cure requires to be used with care, and the cases for its use must be selected, for some patients may be injured by the insufficient nutriment which it affords, while others are greatly benefited by it. The cases in which it answers best are, I think, not those of pure diabetes, but rather those of gouty glycosuria, more especially those in which glycosuria is attended by albuminuria, and where the low specific gravity of the urine, after fermentation, leads to a suspicion of contracted kidneys. In such cases, and also those of gouty kidney where the urine is free from sugar and has a low specific gravity with a trace of albumen, a diet in which milk forms the chief or only ingredient tends to ward off spasmodic dypsncea or the uræmic condition which so frequently occurs from imperfect elimination in old gouty cases.

But we must turn now to another channel of elimination, namely, the bowels ; and this channel is littie, if at all, less important than the kidneys; and, indeed, in the popular mind, it is more important. There is a great deal of truth in the two rules of long life: " Keep your mind easy and your bowels open," and, indeed, easiness of mind depends very much upon the state of the bowels. I remember reading many years ago a story relating to this subject by Norman Macleod, in Good Words, but I have been unable to verify the reference. It was to the effect that a certain Lady Margaret sent a message down late one night to an old clergyman who lived in the manse not far from her castle, to say that she was in great distress about her soul. "And how are Lady Margaret's bowels?" asked the old gentleman. He learned that the bowels were remiss in their duty. "Here are two pills," said the old man to the messenger. "Let Lady Margaret take them to-night, and I will come and talk to her about her soul to-morrow morning." On going up next day the old man found that there was little for him to do, for the bowels had done their work, and, as far as Lady Margaret's feelings went, had restored health to her soul as well as to her body.

There is hardly a room in the house but will become dirtier if you cannot get your dustbin emptied, and there is hardly an organ in the body that does not suffer if the bowels become constipated. Not only the brain, but the heart, liver, lungs, stomach, and kidneys have their functions impaired when the bowels cease to do their duty. Napoleon's disaster at the battle of Leipzig is popularly set down to his having eaten a bun in a hurry and so brought on dyspepsia; but it would be a very curious page of history if we could learn how many wars, how much bloodshed, and how much cruelty have had their origin in imperfect action of the bowels. Washington Irving, in his Lives of the Caliphs, tells of a certain emir named Al Hejagi, who suffered for many years from dyspepsia, and this wretched man distinguished himself, perhaps above all other rulers who have ever lived, in the enormous number of people whom he sentenced to imprisonment and death. He is said to have caused the death of no fewer than 120,000 persons, besides those who fell in battle, and to have left 50,000 in prison when he died himself. How much of all this misery might possibly have been averted by the judicious use of mild aperients it is as impossible for anyone now to tell, as it is to estimate the debt of gratitude which Europe owes to the physician of Louis XIV for the care he took of the bowels of that august monarch.

In mitral disease and in dropsy, either cardiac or renal, the benefit derived from the free use of compound jalap powder is very great, and in his work on Purgative Medicines Dr. Hamilton describes most forcibly the advantages he obtained from purgatives-employed in such a way as merely to clear out the bowels but not to produce violent purging-in typhus, scarlet fever, marasmus, chlorosis, hæmatemesis, hysteria, chorea, and tetanus.

Like all good plans, that of purgation has been carried to great excesses, and its use has frequently degenerated into its abuse, so that it has fallen too much into neglect, and been replaced by the feeding-up system. This, too, is good in its way; but we must always remember that if we want a fire to burn brightly we must not only pile on the coals but also ply the poker to remove the ash. Neither the coals nor the poker alone will do-we must combine them ; and neither the feeding-up system nor the purging system alone will do, but we must combine them in such measure as is necessary for the welfare of our patients. Now, Nature has herself provided a certain regulating mechanism to attain this end ; for, as my friend Dr. Cash has shown, each time that food enters the stomach the bowels receive a certain impetus which is sufficient in healthy people to carry the refuse out and produce an evacuation once a day, the final impetus being usually given by the breakfast, which is sometimes followed by a cigar. In some people, however, the stimulus given by the food is not sufficient, and in these people it may be necessary to give a laxative daily. It is no doubt better to do without this, if possible, and by strict attention to regularity and soliciting Nature at a regular hour every day, whether there be any desire to defæcate or not, the bowels may at length become quite regular.

Exercise in many cases is an adjunct, and the mechanical compression which the intestines undergo from the action of the abdominal walls stimulates them to increased contraction. More especially is this the case if the exercise be of the nature of climbing or riding, for in both of these the abdominal muscles contract with considerable power, while in an ordinary constitutional walk along the level road the bowels receive hardly any compression whatever. Where exercise cannot be obtained, abdominal massage, either by rubbing with the hand or by rolling a cannon ball, covered with chamois leather, over the abdomen, may be useful. A draught of cold or hot water in the morning, or before going to bed at night, by supplying moisture to the contents of the intestines, may liave the desired effect. The hard, indigestible residue of food supplies a healthy mechanical stimulus to the bowels, and I think that in our efforts to save the stomach we sometimes disregard this need of the bowels, and give food which is too soft, too mucilaginous, and too unirritating. Stewed prunes, or stewed 
pears, by the indigestible cellulose which is present in them in the form of skins and gritty grains, figs either raw or stewed, raspberry or strawberry jam by the indigestible seeds which they contain, and marmalade by its orange peel, as well as brown or bran bread by its indigestible husks, all supply a mechanical stimulus to the bowels. But even these sometimes fail, or we find that the stomach objects to them, although the bowels may need them, and we must have recourse to the so-called aperients. Frequently when I prescribe a dinner pill, patients say to me: "But, doctor, it is not natural that I should take medicine every day." I say to that: "Quite true. Nor is it natural that you should keep a cook; and if your cook removes from your food everything that is stimulating to the intestines, you must take something to replace what your cook has taken away. If you will ro back to the manners and customs of the ancient Britons, live in the green wood and eat acorns and pignuts, you will not want any dinner pills.'

Now the dimner pill supplies a very useful stimulus, and I know a man who has taken one every day of his life for forty years, apparently with great benefit to himself. But there are some people who do not seem to thrive on dinner pills, and they either do not get any action at all, or they get too much. In such cases, instead of giving the intestines one great push once a day by the dinner pill, one may give them a series of gentle jogs by adding to each meal a minute quantity of a purgative; and I find one-tenth of a grain of aloin, given with each meal, sometimes succeeds when other measures fail, and even these small doses appear sometimes to be too much.

Now, our bodies are like houses in more than one respect, and it is usually found that although each house may be dusted out once a day, there is a regular cleaning up with extra sweeping once a week; and, in addition to this, there is the spring and autumn cleaning of the whole house. Dinner pills and stimulating diet are like the ordinary daily dusting, and while they may answer for some persons, others find that, in addition, they require a weekly clear out, and if this be not given to them by means of a cholagogue purgative, they have a regular sweep out about once a month by getting a violent migraine with bilious vomiting, and generally they are obliged to fast for at least one day during the continuance of the headache. Besides this, our forefathers used to have a regular clearing out in the spring and autumn not from the bowels but from the blood vessels directly, and they were accustomed, as they said, "to be let blood" in the spring and autumn.

The effect of a cholagogue purgative such as a mild mercurial, as, for example, a small dose of calomel, of blue pill or of grey powder, followed by some saline, is sometimes very remarkable. I have seen a quarter of a grain of calomel, with a seidlitz powder next morning, change as naughty a little girl as you wouldn't wish to see into a perfect little angel, and I well remember a little experience which I had some years ago at a friend's house. One morning at breakfast a little boy was very troublesome, and, instead of taking his oatmeal porridge as he ought to have done, he was nudging and bothering his little sister, who was sitting beside him. I said to my friend, "I think your boy's digestion is out of order." " $\mathrm{Oh}$, no," he said, "it is only naughtiness"; but the naughtiness increased so much that the little boy had to be forcibly removed from the table. As soon as the expulsion was effected my friend said, "You are quite right; his breath does not smell right." In such cases as this I do not know any medi(rine that is better than some Gregory's powder, because it has both a moral effect and a physical action. Its nasty taste when administered as a punishment is wholesome morally. while its action upon the liver and digestion is most useful physically.

Not infrequently adults suffer from nervous irritability, depression, weakness, and inability to do anything, and this is put down on the part of their friends, and frequently of their doctors, to neurasthenia and hypochondriasis. They are treated with nervine tonics, nervine sedatives, change of scene, change of air, baths, waters, advice or scolding, and all to no good. Tervous and depressed they still remain. In some of these cases one may notice a large amount of mucus in the motions, and sometimes there appear to be actual casts of the intestines, long membranous looking shreds ap- parently tubular in their nature. This condition has been described by the late Sir James Simpson under the name of membranous enteritis, and it is not only usually said to be associated with hypochondriasis, but often it is looked upon as the consequence rather than the cause of the nervous condition, which is certainly its usual concomitant. But it is of no use here to treat the nerves. If you wish for any good result you must treat the bowels. In some, probably in many, cases it depends upon the partial constriction of the intestine near the junction of the sigmoid flexure with the rectum. The motions, lodging here, tend to cause an inflammatory condition of the mucous membrane and profuse secretion of mucus, which either simply coats the fæcal masses or forms a kind of false membrane. This condition may be due to actual constriction of the lumen of the gut or to a diminution in its calibre from pressure. In children prolapse of the rectum is a very common thing. In adults it is comparatively rare, but in them a tendency remains, not to prolapse of the rectum externally, but of the sigmoid flexure into the rectum, and this condition may give rise to great nervous disturbance, lasting for years and perhaps indefinitely, unless its existence be suspected and the proper treatment adopted.

One useful remedy - strongly recommended by Mr. Crippsis the injection of 2 to 4 ounces of cold water immediately after a motion. This is to be retained, and has, as he expressed it, the tonic effect of a cold bath upon the intestine, increasing the contractile power and lessening the tendency to prolapse. I once saw a case of this sort at intervals for two or three years without ever suspecting its nature. It occurred in a man from New Zealand who had been accustomed to a great deal of horse exercise, frequently riding 40 miles a day. He began to suffer from neurasthenia, hypochondriasis, loss of appetite, failing strength, and emaciation. In fact, he presented almost the typical aspect of the hysterical girls who are so well treated by the Weir-Mitchell plan, and, in consequence of this, I advised him to undergo a course of massage. This he did two or three times with very little good, until, by my advice, he went to Dr. Eccles, who discovered the real cause of his illness, and, by the judicious application of massage to the intestines, completely restored him to health.

But it is not only in the upper part of the intestine and in the sigmoid flexure that hindrances to elimination exist. Even when the fæcal masses have reached the rectum there may be difficulties in the way of their expulsion. It is usually imagined that nothing can be simpler than to empty the rectum, and yet one of the most grateful letters I ever had in my life from a patient was for giving instructions in this matter. As the poor lady said, she had for many years had great difficulty in emptying the bowels, and no one had ever taken the trouble to instruct her as to the mode of overcoming it. The fact is, one often forgets that the pressure of the abdominal muscles acts in the same direction in defæcation as in parturition, tending to drive the fæcal mass towards the coccyx, and in order that it may be evacuated its course must be finally directed somewhat forward. This change in direction is effected by the muscles of the pelvic floor, but if those are lax, as frequently occurs in persons of sedentary habits, and more especially in women who have had large families, the fæces, instead of being expelled, may accumulate in and distend the rectum. This accumulation is greatly favoured by the construction of water-closets, as in sitting upon them the spine is usually at a right angle with the thighs, the legs are close together, and the pelvic floor is not put upon the stretch. When the body is inclined at an acute angle forward the pelvic floor becomes tighter, and this is still more the case when the crouching or squatting attitude is adopted, which is naturally assumed when emptying the bowels in the open air. In cases where defæcation is difficult this attitude is to be recommended, and a very low commode-pan or chamber-pot should be used in place of the ordinary closet. Should this be insufficient, pressure with the liand close under the tip of the coccyx will tend to force the fæcal mass forward and greatly facilitate its expulsion.

In relation to the complete evacuation of the bowels, I have received a very interesting communication from my friend Dr. Batten: "Mr. R. suffered from pruritus ani, with slight eczema and a small pile. On examining the rectum a small piece of fæces, the size of a flat bean, was found just inside the anal orifice, not only on one occasion, but whęnever an 
examination was made. If the fæces were removed before going to bed (the pruritus occurred more at night) the irritation did not occur. Remembering your plan of treatment with administration of small doses of aloes, I gave them, but without any success. On inquiry, I found that Mr. R.'s bowels were moved with great regularity every morning, and that the motion was not a formed one-at all events, not the last portion of it. Upon this I reasoned that Mr. R.'s failure to entirely empty the bowel was due to the want of solidity of the motion not giving the bowel anything to contract upon. I therefore ordered him occasional doses of lime water to be taken sufficiently often to cause a formed motion. The result was very satisfactory. The bowel contracted on and expelled the solid motion completely. I think, in our desire to keep the bowels regular, we overlook the disadvantages of fluid instead of a solid motion."

Before concluding this lecture, I will mention a plan which I have found of very great service either in cases of cardiac disease, in fevers, or in conditions of extreme weakness where the feebleness of the heart made it very advisable that the patient should use as little exertion as possible. It frequently happens that patients strongly object to use a bedpan, and assert, sometimes with a considerable amount of truth, that they are unable to empty the bowels satisfactorily in the recumbent posture. A great deal of the risk connected with the use of a commode arises from the fact that when they use it they generally have to get out of bed and into it again. In these cases I adopt a plan, which I suppose many others have used also, but which I have never seen described. It is to have a strong platform made of rough wood, of such a height that the commode, when placed upon it, is level with the bed. A large, strong packing box, sawn to the proper height, may answer, or, if this is not at hand, any carpenter can put together a rough but strong construction of the kind needed. If nothing else is at hand, the drawer of a wardrobe turned upside down will do, but it must be supporied from below by books or pillows piled up within it, so as to prevent the bottom of it from breaking through, as usually it is not strong enough to support the weight. The commode being pushed close to the bedside, the patient has simply to slew himself round upon it. The body is raised, and the legs are allowed to hang down. After the bowels liave been evacuated, he is rolled round on his side into bed. During the whole process no change is ever made in the level of the patient, the only alteration being in the relative position of the trunk and legs with reference to his pelvis. Perhaps some of the new devices for raising the patient bodily from the bed might do better than this, but generally they are not at hand, and the plan which I have mentioned can always be followed, as some kind of platform sufficiently strong to serve the purpose can be made with boards, boxes, or footstools in every house.

In this lecture I have not attempted to go over anything like the whole field which its title would cover, because I found this to be impossible in the time at my disposal. I have, therefore, attempted to deal only with such points as have more of a practical than a theoretical interest. In concluding it, I thank you most sincerely, Mr. President and gentlemen, for the great honour you have done me in asking me to deliver this lecture, and to beg you to forgive the deficiencies in it, of which no one is more conscious than myself.

The Four Years' CURRICULUM IN AMERICA.-In addition to the University of Pennsylvania, which, as already mentioned, now stands pledged to a four years' curriculum, other American schools have adopted the same enlightened policy. The authorities of the Medical School of Harvard University have passed a resolution that, in the case of all students entering on or after September, 1892, the regular course necessary to obtain the M.D. degree shall be four years. The Kansas City Medical College has recently decided to make a four years' curriculum, "with three full courses at college," compulsory.

LAdY LUCY Hicks-Beach opened, on June 10th, at South Grove, Highgate, a honie for children in connection with the Santa Claus Society. The home is intended chiefly for cases of hip and spinal diseases, and for those children who, though otherwise well enough to go to a convalescent home, require slight surgical treatment and nursing.

\section{LECTURES}

on

\section{GOÎTRE; ITS PATHOLOGY, DIAGNOSIS, ANI) SURGICAL TREATMENT.}

Delivered at the Royal College of Surgeons of England. By JAMES BERRY, B.S., F.R.C.S.,

Professor of Surgery and Pathology, Royal College of Surgeons; Surgeon to the Royal Free Hospital and to the Alexandra Hospital for Children with Hip Disease.

LECTURE II.

Parenchymatous Goítre, Treatment of.-- Internal RemediesExternal Applications-Injection, Dangers of-Seton-Ligature of Thyroid Arteries-Division of Isthmus-Evtirpation Total; Partial-Methods of Performing Extirpation-Skin Incision-Treatment of Veins, Muscles, Capsule, Arteries, Isthmus-Aseptic Treatment of Wound-Importance of not Irrigating-Suture-After-treatment-Mikulicz's ResectionKocher's Resection-Comparison of-Advantages of EachResults-Resection of Isthmus.

[IT was stated that this lecture would be devoted to the treatment of parenchymatous goître. After some remarks upon internal remedies and external applications suitable for this variety of goître, the subject of injection was discussed.]

The object which is aimed at in the injection of a parenchymatous goitre is to cause sufficient inflammation to obliterate some of the minute vesicles of the gland. Possibly also there is some direct solvent action upon the colloid contents of the vesicles which may promote absorption. It is obvious therefore that parenchymatous and cystic goitres are more readily amenable to treatment by injection than the harder and more solid forms.

The materials that have been used for injection are very numerous. That which occupies the foremost rank is undoubtedly iodine. Alcohol, arsenical solutions, and those of perchloride of iron, osmic acid, iodoform, and others, have been recommended, but probably none of them are superior to iodine. The best directions that I know of for the performance of the injection of iodine are those given by Dr. Felix Semon $;^{1}$ they are too well known to require further mention. That the directions given by him are excellent, there can I think be but little doubt, and anyone who wishes to treat a goître by injection of iodine cannot do better than follow them. It is certain that in a large proportion of cases a successful result ensues, but there is equally little doubt that very often the treatment is unsuccessful. A large number of cases have been recorded in which various complications, even death itself, have followed the operation. The injection may, and probably does, at first produce increased swelling of the gland; this may cause dyspnœe or aggravate any that may bealready present. The injection may cause suppuration, which in its turn may lead to death. Many such cases have been reported to me; most of them have not been published. In these the evil results were due to inflammation and suppuration in the neck, and death occurred after several days, weeks, or months. A considerable number of cases have, however, been recorded in which death ensued much more speedily, before suppuration had had time to manifest itself.

Dr. Rose ${ }^{2}$ formerly of Zürich, says that he himself knows of not less than six instances in which surgeons have lost healthy patients from injecting iodine into a goitre, death occurring either upon the operating table or within a few hours after the injection. Dr. Seitz, ${ }^{3}$ in a monograph upon death from goître, mentions the following cases :

The first is that of a woman under the care of Dr. Schwalbe the injection of ten drops of tincture of iodine into a small goître caused, after a few minutes, numbness, and then paralysis of the left arm and leg, partial loss of speech, slight

1 Heath's Dictionary of Surgery, Art. Disease of Thyroid Gland. 2 Der Kropftod und die Radicalcur der Kröpfe, Arch. f. klin. Chir. Bd. xxii.

3 Der Kropftod durch Stimmbandlähmung, Arch. f. klin. Chir., xxix, i. 